\title{
Food insecurity is associated with unhealthy dietary practices among US veterans in California
}

\author{
Monideepa B Becerra ${ }^{1, *}$, Christina M Hassija ${ }^{2}$ and Benjamin J Becerra ${ }^{3}$ \\ 'Department of Health Science and Human Ecology, California State University, San Bernardino, 5500 University \\ Parkway, San Bernardino, CA 92407, USA: ²Department of Psychology, California State University, San Bernardino, \\ San Bernardino, CA, USA: ${ }^{3}$ School of Allied Health Professions, Loma Linda University, Loma Linda, CA, USA
}

Submitted 31 December 2015: Final revision received 22 June 2016: Accepted 7 July 2016: First published online 30 August 2016

\begin{abstract}
Objective: US veterans (hereafter, 'veterans') are at risk for being overweight or obese and associated unhealthy behaviours, including poor diet; although limited studies have examined the underlying factors associated with such outcomes. As such, the present study evaluated the association between food insecurity and dietary practices among veterans.

Design: A secondary analysis of cross-sectional data from the California Health Interview Survey (2009, 2011/2012) was conducted. Survey weights were applied to identify univariate means, population estimates and weighted percentages. Bivariate analyses followed by survey-weighted negative binomial regression were used to model the association between food insecurity and dietary practices of fruit, vegetable, fast food and soda intakes.

Setting: California Health Interview Survey 2009-2011/2012.

Subjects: The present study included a total of 11011 veterans from California.

Results: Nearly $5 \%$ of the studied veteran population reported living in poverty with food insecurity. Compared with those at or above the poverty level and those in poverty but food secure, the mean intakes of fruits and vegetables were lower, while the mean intakes of soda and fast foods $(P$ for trend $<0.05)$ were higher among veterans living in poverty with food insecurity. Food insecurity was associated with 24 and $142 \%$ higher average consumption of fast foods and soda, respectively, and $24 \%$ lower fruit intake.

Conclusions: Food insecurity remains a burden among veterans and is associated with unhealthy dietary practices. Targeted interventions to improve diet quality are imperative.
\end{abstract}

Keywords
Food insecurity
Veterans
Diet
California Health Interview Survey
The empirical evidence highlights US veterans (hereafter, referred to as 'veterans') as an at-risk population for being overweight or obese ${ }^{(1,2)}$. A recent study noted that approximately 37 and $33 \%$ of women and men veterans are obese, respectively ${ }^{(3)}$, while others demonstrated higher prevalence of overweight status ${ }^{(4)}$ and greater waist circumference among veterans ${ }^{(1)}$ as compared with the civilian population. Similarly, recent studies have demonstrated increased weight gain among veterans post military discharge $^{(1)}$, thus increasing their long-term weight-related health complications ${ }^{(5)}$.

One potential driving factor for such prevalence of overweight and obesity among veterans may be their dietary practices. For instance, in a study among veterans with type 2 diabetes in Washington State, Nelson and co-workers demonstrated that $42 \%$ of the study population reported consumption of a high-fat diet ${ }^{(6)}$. Similarly, in another study utilizing the 2000 Behavioral Risk Factor Surveillance System, Wang et al. noted that $40 \%$ of the study sample reported change to a low-energy and low-fat diet in order to lose weight ${ }^{(7)}$, demonstrating a low adherence to healthy dietary practices in the veteran population.

In recent years, food security, defined by the US Department of Agriculture as 'access by all people at all times to enough food for active, healthy life ${ }^{,(8)}$, has been highlighted as a significant contributor to population health, including diet. For example, a study among Inuit communities demonstrated that household food insecurity was related to lower scores on the Healthy Eating Index, lower consumption of fruits, vegetables, dairy products and grains, and higher intake of energy from high-sugar foods ${ }^{(9)}$. Similarly, food insecurity has been associated with lower nutrient intakes among women ${ }^{(10)}$ and increased consumption of fruit juices among low-income adults ${ }^{(11)}$. 
Although current evidence on food insecurity and the putative impact on diet among veterans is limited, a recent study found $24 \%$ of veterans in the Veterans Aging Cohort Study as food insecure ${ }^{(12)}$, while another study among veterans who served in the Iraq and Afghanistan wars noted $25 \%$ had low food security and $12 \%$ had very low food security in the past year ${ }^{(13)}$. In the present study we aimed to address such a gap in the literature and thus our objective was to utilize data from a population-based survey to determine the relationship between sociodemographic characteristics, food insecurity and dietary practices among veterans.

\section{Methods}

\section{Data source}

We utilized the 2009, 2011/2012 California Health Interview Survey (CHIS). The CHIS, a biennial survey with selfreported data, is considered the largest state health survey. The CHIS utilizes a random digit-dial system (including both landlines and cell phones), with further methodological details found elsewhere ${ }^{(14)}$. In the current study, respondents who reported serving on active duty in the US Armed Forces (and for those whom length of stay in the military could be ascertained) were defined as veterans.

\section{Measures}

The outcome variables in the present study were past week consumption of fast foods, soda, fruits and vegetables. The primary independent variable was food insecurity, defined by CHIS-provided variables: living at or above $200 \%$ of the federal poverty level (FPL); living at less than $200 \%$ of the FPL and food secure; and living at less than $200 \%$ of the FPL and food insecure. The CHIS asked the following questions on food insecurity to those living below $200 \%$ of the FPL or reporting 'unknown' to poverty level and created a food security variable, which was utilized in the present study: (i) 'The food that (I/we) bought just didn't last, and (I/we) didn't have money to get more'; (ii) '(I/We) couldn't afford to eat balanced meals'; (iii) 'In the last 12 months, did you or other adults in your household ever cut the size of your meals or skip meals because there wasn't enough money for food? How often did this happen? Almost every month, some months but not every month, or only in 1 or 2 months?'; (iv) 'In the last 12 months, did you ever eat less than you felt you should because there wasn't enough money to buy food?'; and finally (v) 'In the last 12 months, were you ever hungry but didn't eat because you couldn't afford enough food?'

Covariates for the study included Supplemental Nutrition Assistance Program (SNAP) participation (yes, no), age (18-24 years, 25-44 years, 45-64 years, 65 years or older), sex (male, female), race/ethnicity (African American, Asian American/Pacific Islander, Hispanic,
Non-Hispanic White, other), marital status (currently married, not currently married), education level (high school or less, some college/vocational/associate degree, bachelor's or more), employment status (currently unemployed, currently employed), risk behaviours (smoke and binge drink, smoke or binge drink, none), weight status (overweight or obese, not overweight or obese), general health status (fair/poor, excellent/very good/good), geographic setting (rural, urban) and year (2009, 2011). Overweight or obese was based on a BMI of $25 \cdot 0 \mathrm{~kg} / \mathrm{m}^{2(15)}$. Risk behaviours were identified as being a current smoker and/or binge drinking in the past 12 months.

\section{Data analysis}

We utilized the statistical software package Stata version 14 for all statistical analyses. With the exception of nonparametric tests, all analyses were survey-weighted and $\alpha$ level less than 0.05 was used to denote significance. To determine the distribution of each dietary practice by each population characteristic, we conducted bivariate analyses using the non-parametric Kruskal-Wallis test for differences in medians with ties. If a significant difference was detected between three or more groups, a post boc multiple comparisons test with Dunn's pairwise comparisons using the Holm-Sidak adjustment was utilized. Cuzick's non-parametric test for trend across ordered groups was conducted to assess for trend in dietary practices across poverty and food security categories. Finally, we used negative binomial regression to model the association between rate of dietary practices with poverty and food security after adjusting for control variables.

\section{Results}

Our study included a total sample size of 11011 veterans, reflecting an extrapolated average population estimate of 2234186 . In the study population, $4.89 \%$ of veterans were below $200 \%$ of the FPL and food insecure, and $2.35 \%$ reported participating in SNAP. In addition, $71 \cdot 13 \%$ of the population was overweight or obese with additional characteristics displayed in Table 1.

As shown in Table 2, veterans living in poverty and with food insecurity reported the highest mean intakes of fast foods and soda while reporting the lowest mean intakes of fruits and vegetables. Significant differences in intake of such dietary outcomes by each poverty and food security level were further noted (Kruskal-Wallis test for differences in median, $P<0.0001 ; P$ for trend $<0.05$ ).

As displayed in Table 3, those who lived below $200 \%$ of the FPL and were food insecure reported, on average, 24 and $142 \%$ higher mean intake of fast foods and soda in the past week, respectively, compared with those living at or above $200 \%$ of the FPL. Living in poverty and being food insecure, as shown in Table 4, was also significantly 
Table 1 Characteristics of the population of US veterans ( $n$ 11011; N2234 186), California Health Interview Survey (2009, 2011/2012)

\begin{tabular}{|c|c|c|c|}
\hline & $n$ & $\begin{array}{l}\text { Weighted } \\
\%\end{array}$ & $\begin{array}{l}\text { Average } \\
\text { annual } N\end{array}$ \\
\hline \multicolumn{4}{|l|}{ Poverty and food security } \\
\hline $\begin{array}{l}\text { Below } 200 \% \text { of the FPL, } \\
\text { food insecure }\end{array}$ & 443 & 4.89 & 109173 \\
\hline $\begin{array}{l}\text { Below } 200 \% \text { of the FPL, } \\
\text { food secure }\end{array}$ & 1564 & $13 \cdot 87$ & 309875 \\
\hline $\begin{array}{l}\text { At or above } 200 \% \text { of the } \\
\text { FPL }\end{array}$ & 9004 & $81 \cdot 24$ & 1815138 \\
\hline \multicolumn{4}{|l|}{ SNAP participation } \\
\hline Yes & 141 & $2 \cdot 35$ & 52433 \\
\hline No & 10870 & 97.65 & 2181753 \\
\hline \multicolumn{4}{|l|}{ Age (years) } \\
\hline $18-24$ & 78 & 3.04 & 67898 \\
\hline $25-44$ & 849 & $18 \cdot 49$ & 413122 \\
\hline $45-64$ & 3295 & $35 \cdot 70$ & 797662 \\
\hline 65 or older & 6789 & $42 \cdot 77$ & 955504 \\
\hline \multicolumn{4}{|l|}{ Sex } \\
\hline Male & 10196 & $92 \cdot 10$ & 2057707 \\
\hline Female & 815 & 7.90 & 176480 \\
\hline \multicolumn{4}{|l|}{ Race/ethnicity } \\
\hline Hispanic & 432 & $8 \cdot 39$ & 187554 \\
\hline $\begin{array}{l}\text { Asian American/Pacific } \\
\text { Islander }\end{array}$ & 321 & $5 \cdot 17$ & 115460 \\
\hline African American & 618 & 8.45 & 188787 \\
\hline Non-Hispanic White & 9037 & $70 \cdot 49$ & 1574981 \\
\hline Other & 603 & 7.49 & 167405 \\
\hline \multicolumn{4}{|l|}{ Marital status } \\
\hline Currently married & 6524 & $66 \cdot 86$ & 1493753 \\
\hline \multirow{2}{*}{\multicolumn{4}{|c|}{ Education level }} \\
\hline & & & \\
\hline High school or less & 2611 & 31.41 & 701735 \\
\hline $\begin{array}{l}\text { Some college/vocational/ } \\
\text { associate degree }\end{array}$ & 3584 & $31 \cdot 70$ & 708190 \\
\hline Bachelor's or more & 4816 & $36 \cdot 89$ & 824262 \\
\hline \multicolumn{4}{|l|}{ Employment status } \\
\hline Currently unemployed & 7088 & 51.89 & 1159245 \\
\hline Currently employed & 3923 & $48 \cdot 11$ & 1074942 \\
\hline \multicolumn{4}{|l|}{ Weight status } \\
\hline Overweight/obese & 7534 & $71 \cdot 13$ & 1589217 \\
\hline Not overweight/obese & 3477 & $28 \cdot 87$ & 644969 \\
\hline \multicolumn{4}{|l|}{ General health status } \\
\hline Fair/poor & 2226 & $18 \cdot 84$ & 421002 \\
\hline Excellent/very good/good & 8785 & $81 \cdot 16$ & 1813185 \\
\hline \multicolumn{4}{|l|}{ Risk behaviour } \\
\hline Smoke and binge drink & 441 & $6 \cdot 80$ & 658581 \\
\hline Smoke or binge drink & 2685 & $29 \cdot 48$ & 658581 \\
\hline None & 7885 & $63 \cdot 72$ & 1423696 \\
\hline \multicolumn{4}{|l|}{ Geographic setting } \\
\hline Rural & 2444 & 14.79 & 330376 \\
\hline Urban & 8567 & $85 \cdot 21$ & 1903810 \\
\hline \multicolumn{4}{|l|}{ Year } \\
\hline 2011 & 4953 & 48.52 & 1083968 \\
\hline 2009 & 6058 & 51.48 & 1150218 \\
\hline
\end{tabular}

FPL, federal poverty level; SNAP, Supplemental Nutrition Assistance Program.

associated with reporting an average of $24 \%$ lower mean fruit intake in the past week, in comparison to living at or above $200 \%$ of the FPL. Living in poverty (below $200 \%$ of the FPL) but being food secure did not yield a significant association with any of the dietary behaviours assessed.

Our results further showed several factors to be significantly associated with past week intakes of fast foods,
Table 2 Mean intakes of fast foods, soda, fruits and vegetables (servings/week), by poverty and food security level, among the population of US veterans, California Health Interview Survey (2009, 2011/2012)

\begin{tabular}{llllll}
\hline & $\begin{array}{c}\text { Fast } \\
\text { foods }\end{array}$ & Soda & Fruits & Vegetables \\
\hline $\begin{array}{l}\text { Poverty and food security } \\
\text { Below } 200 \% \text { of the FPL, food } \\
\text { insecure }\end{array}$ & 2.21 & 3.88 & 4.44 & 5.70 \\
$\begin{array}{l}\text { Below } 200 \% \text { of the FPL, food } \\
\quad \text { secure }\end{array}$ & 1.62 & 2.25 & 6.41 & 6.08 \\
$\quad$ At or above 200\% of the FPL & 1.52 & 1.43 & 7.08 & 6.85 \\
\hline FPL, federal poverty level. & & & & \\
\hline
\end{tabular}

soda, fruits and vegetables (Tables 3 and 4). For example, those who participated in SNAP had on average $31 \%$ lower intake of fruits than those who did not. For both fast food and soda consumption, decreasing age was significantly associated with an increasing mean intake of such dietary items, with the highest increase noted among those aged 18-24 years. Similarly, males, as compared with females, reported on average higher intakes of fast foods and soda but lower intakes of fruits and vegetables. Decreasing education level was also associated with increasing average intake of both fast foods and soda, and decreasing intake of both fruits and vegetables, while being unemployed was associated only with a 16\% decrease in average consumption of fast foods.

When evaluating dietary practices by ethnic group, as compared with Whites, Latinos had on average 19 and $34 \%$ lower consumption of fruits and vegetables, respectively, while Asian American/Pacific Islanders had a 14\% lower intake of vegetables. African Americans, as compared with Whites, further had 36\% higher and $9 \%$ lower soda and vegetable intake, respectively.

Both fair/poor general health status and overweight/ obesity status yielded significant results only for soda intake, although in the opposite direction. For instance, overweight/obese individuals, as compared with those who were not, reported on average $17 \%$ lower consumption of soda. On the other hand, those with fair/poor health status on average had $32 \%$ higher intake of soda $v$. those who reported good to excellent health status. A negative role of risk behaviours was also found, with those reporting being a current smoker and/or binge drinking in the past 12 months having lower fruit and vegetable consumption while having a higher intake of soda. Study participants residing in rural areas on average consumed $25 \%$ less fast food per week.

\section{Discussion}

Despite the high prevalence of CVD and clinical risk factors, such as obesity, among veterans ${ }^{(1,2)}$, few studies have accounted for barriers to healthy dietary practices in this population. In the present study we addressed this 
Table 3 Rate ratio (RR) and $95 \%$ confidence interval of fast food and soda intake in the past week among the population of US veterans, California Health Interview Survey $(2009,2011 / 2012)$

\begin{tabular}{|c|c|c|c|c|c|}
\hline & \multicolumn{2}{|c|}{ Fast foods } & \multicolumn{3}{|c|}{ Soda } \\
\hline & $\mathrm{RR}$ & $95 \% \mathrm{Cl}$ & $\mathrm{RR}$ & & $95 \% \mathrm{Cl}$ \\
\hline \multicolumn{6}{|l|}{ Poverty and food security } \\
\hline Below $200 \%$ of the FPL, food insecure & $1.24^{\star \star}$ & $1.07,1.44$ & $2 \cdot 42^{\star \star \star}$ & & $1.74,3.37$ \\
\hline Below $200 \%$ of the FPL, food secure & 0.99 & $0.86,1.13$ & $1 \cdot 17$ & & $0.93,1.47$ \\
\hline At or above $200 \%$ of the FPL & \multicolumn{2}{|r|}{ טור, 1000 } & \multirow{2}{*}{\multicolumn{3}{|c|}{ Ref. }} \\
\hline SNAP participation & & & & & \\
\hline Yes & 0.86 & $0.66,1.13$ & 0.85 & & $0.52,1.40$ \\
\hline No & \multicolumn{2}{|c|}{ Ref. } & \multicolumn{3}{|c|}{ Ref. } \\
\hline \multicolumn{6}{|l|}{ Age (years) } \\
\hline $18-24$ & $2 \cdot 23^{\star \star}$ & $1.45,3.43$ & $2 \cdot 94^{\star \star}$ & & $1.71,5.03$ \\
\hline $25-44$ & $1.94^{\star \star *}$ & $1.67,2 \cdot 24$ & $2 \cdot 16^{\star \star \star}$ & & $1.68,2.78$ \\
\hline $45-64$ & $1.47^{\star \star *}$ & $1.26,1.72$ & $1 \cdot 31^{*}$ & & $1.06,1.62$ \\
\hline 65 or older & \multicolumn{2}{|c|}{ Ref. } & \multicolumn{3}{|c|}{ Ref. } \\
\hline \multicolumn{6}{|l|}{ Sex } \\
\hline Male & $1 \cdot 28^{\star *}$ & $1.08,1.51$ & $2 \cdot 10^{\star \star \star}$ & & $1.51,2.92$ \\
\hline Female & \multicolumn{2}{|c|}{ Ref. } & \multicolumn{3}{|c|}{ Ref. } \\
\hline \multicolumn{6}{|l|}{ Race/ethnicity } \\
\hline Latino & 0.97 & $0.80,1.16$ & 0.94 & & $0.72,1.23$ \\
\hline Asian American/Pacific Islander & 0.83 & $0.67,1.03$ & 0.77 & & $0.50,1.20$ \\
\hline African American & 1.06 & $0.91,1.24$ & $1 \cdot 36^{*}$ & & $1.03,1.79$ \\
\hline Other & 0.99 & $0.85,1.14$ & 1.03 & & $0.80,1.33$ \\
\hline Non-Hispanic White & \multicolumn{2}{|c|}{ Ref. } & \multicolumn{3}{|c|}{ Ref. } \\
\hline \multicolumn{6}{|l|}{ Marital status } \\
\hline Currently married & 0.94 & $0.85,1.05$ & 0.90 & & $0.76,1.08$ \\
\hline Not currently married & \multicolumn{2}{|c|}{ Ref. } & \multicolumn{3}{|c|}{ Ref. } \\
\hline \multicolumn{6}{|l|}{ Education level } \\
\hline High school or less & $1 \cdot 33^{\star \star \star}$ & $1.16,1.52$ & $1.63^{\star \star \star}$ & & $1 \cdot 31,2.03$ \\
\hline Some college/vocational/associate degree & $1.32^{* * *}$ & $1.17,1.49$ & $1.30^{\star \star}$ & & $1.10,1.54$ \\
\hline Bachelor's or more & \multicolumn{2}{|r|}{ (1.18, } & \multicolumn{3}{|c|}{ Ref. } \\
\hline Employment status & & & & & \\
\hline Currently unemployed & $0.84^{*}$ & $0.74,0.95$ & 0.88 & & $0.74,1.05$ \\
\hline Currently employed & & & & Ref. & \\
\hline Weight status & & & & & \\
\hline Overweight/obese & 1.08 & $0.95,1.22$ & $0.83^{*}$ & & $0.72,0.97$ \\
\hline Not overweight/obese & & & & Ref. & \\
\hline General health status & & & & & \\
\hline Fair/poor & 1.08 & $0.92,1.26$ & $1 \cdot 32^{*}$ & & $1.09,1.60$ \\
\hline Excellent/very good/good & & & & - & \\
\hline Risk behaviour & & & & & \\
\hline Smoke and binge drink & $1 \cdot 18$ & $0.95,1.47$ & $1.55^{*}$ & & $1 \cdot 13,2 \cdot 13$ \\
\hline Smoke or binge drink & 1.02 & $0.91,1.14$ & $1 \cdot 13$ & & $0.94,1.35$ \\
\hline None & & & & Ref. & \\
\hline Geographic setting & & & & & \\
\hline Rural & $0 \cdot 75^{\star \star \star}$ & $0.67,0.85$ & 0.92 & & $0.79,1.08$ \\
\hline Urban & & & & Ref. & \\
\hline Year & & & & & \\
\hline 2011 & 1.04 & $0.95,1.13$ & 0.93 & & $0.81,1.08$ \\
\hline 2009 & & & & Ref. & \\
\hline
\end{tabular}

FPL, federal poverty level; SNAP, Supplemental Nutrition Assistance Program; Ref., reference category. ${ }^{\star} P<0.05,{ }^{* *} P<0.005,{ }^{* * *} P<0.0001$.

gap in the literature, with further emphasis on the role of food insecurity on fast food, soda, fruit and vegetable consumption among veterans in California utilizing a population-based survey.

In our study, a major finding was the significant inverse relationship of food insecurity with fruit intake and the positive association with fast food and soda intakes. Such results are comparable to studies among other vulnerable populations. For example, in a study among 1874 lowincome adults, Mello and co-workers noted that foodinsecure participants were more likely to have high fat intake, as well as juice intake ${ }^{(11)}$. Similarly, in a study among rural women, food insecurity was significantly related to lower consumption of fruits and vegetables ${ }^{(16)}$, while among food pantry participants, food security was related to increased fruit, vegetable and fibre intakes ${ }^{(17)}$. Additionally, economic analysis has demonstrated that the low cost of high-fat and high-energy-dense foods could further be driving vulnerable populations away from healthier items that usually are more expensive ${ }^{(18-20)}$.

While similar studies among veterans remain limited, upon analysis of interviews with sixty-four veterans Smith and colleagues noted that eating behaviours adapted during food insecurity at the time of military service 
Table 4 Rate ratio (RR) and $95 \%$ confidence interval of fruit and vegetable intake in the past week among the population of US veterans, California Health Interview Survey $(2009,2011 / 2012)$

\begin{tabular}{|c|c|c|c|c|c|c|}
\hline & \multicolumn{3}{|c|}{ Fruits } & \multicolumn{3}{|c|}{ Vegetables } \\
\hline & $\mathrm{RR}$ & & $95 \% \mathrm{Cl}$ & $\mathrm{RR}$ & & $95 \% \mathrm{Cl}$ \\
\hline \multicolumn{7}{|l|}{ Poverty and food security } \\
\hline Below $200 \%$ of the FPL, food insecure & $0 \cdot 76^{\star \star}$ & & $0.63,0.90$ & 0.88 & & $0.74,1.05$ \\
\hline Below $200 \%$ of the $\mathrm{FPL}$, food secure & 1.01 & & $0.88,1 \cdot 14$ & \multirow{2}{*}{\multicolumn{3}{|c|}{ Ref. }} \\
\hline At or above $200 \%$ of the FPL & \multicolumn{3}{|c|}{ Ref. } & & & \\
\hline \multicolumn{7}{|l|}{ SNAP participation } \\
\hline Yes & $0.69^{*}$ & & $0.48,0.98$ & 1.08 & & $0.72,1.63$ \\
\hline No & \multicolumn{3}{|c|}{ Ref. } & \multicolumn{3}{|c|}{ Ref. } \\
\hline \multicolumn{7}{|l|}{ Age (years) } \\
\hline $18-24$ & 0.98 & & $0.68,1.43$ & 0.97 & & $0.77,1.24$ \\
\hline $25-44$ & 0.94 & & $0.82,1.09$ & 1.08 & & $0.96,1.22$ \\
\hline $45-64$ & 0.94 & & $0.87,1.02$ & 1.03 & & $0.95,1.11$ \\
\hline 65 or older & \multicolumn{3}{|c|}{ Ref. } & \multicolumn{3}{|c|}{ Ref. } \\
\hline \multicolumn{7}{|l|}{ Sex } \\
\hline Male & $0.79^{\star}$ & & $0.67,0.94$ & $0.74^{\star \star \star}$ & & $0.67,0.82$ \\
\hline Female & \multicolumn{3}{|c|}{ Ref. } & \multicolumn{3}{|c|}{ Ref. } \\
\hline \multicolumn{7}{|l|}{ Race/ethnicity } \\
\hline Latino & $0.81^{\star \star}$ & & $0.72,0.92$ & $0.66^{\star \star \star}$ & & $0.59,0.73$ \\
\hline Asian American/Pacific Islander & 1.03 & & $0.86,1.24$ & $0.86^{*}$ & & $0.77,0.95$ \\
\hline African American & 0.91 & & $0.80,1.03$ & $0.91^{*}$ & & $0.83,0.98$ \\
\hline Other & 1.04 & & $0.88,1.22$ & 0.94 & & $0.86,1.04$ \\
\hline Non-Hispanic White & \multicolumn{3}{|c|}{ Ref. } & \multicolumn{3}{|c|}{ Ref. } \\
\hline \multicolumn{7}{|l|}{ Marital status } \\
\hline Currently married & 1.01 & & $0.94,1.09$ & 1.06 & & $0.99,1.12$ \\
\hline Not currently married & \multicolumn{3}{|c|}{ Ref. } & \multicolumn{3}{|c|}{ Ref. } \\
\hline \multicolumn{7}{|l|}{ Education level } \\
\hline High school or less & $0.76^{\star \star \star}$ & & $0.69,0.82$ & $0.79^{\star \star \star}$ & & $0.75,0.84$ \\
\hline Some college/vocational/associate degree & $0.90^{*}$ & & $0.83,0.99$ & $0.88^{\star \star}$ & & $0.82,0.95$ \\
\hline Bachelor's or more & & Ref. & & & Ref. & \\
\hline Employment status & & & & & & \\
\hline Currently unemployed & 0.98 & & $0.89,1.07$ & 1.02 & & $0.95,1.10$ \\
\hline Currently employed & & Ref. & & & Ref. & \\
\hline Weight status & & & & & & \\
\hline Overweight/obese & 0.98 & & $0.91,1.05$ & 0.94 & & $0.87,1.00$ \\
\hline Not overweight/obese & & Ref. & & & Ref. & \\
\hline General health status & & & & & & \\
\hline Fair/poor & 0.94 & & $0.85,1.03$ & 0.94 & & $0.86,1.03$ \\
\hline Excellent/very good/good & & Ref. & & & Ref. & \\
\hline Risk behaviour & & & & & & \\
\hline Smoke and binge drink & $0.69^{*}$ & & $0.53,0.89$ & $0 \cdot 78^{\star *}$ & & $0.67,0.90$ \\
\hline Smoke or binge drink & $0.91^{*}$ & & $0.84,0.99$ & $0.92^{*}$ & & $0.86,0.98$ \\
\hline None & & Ref. & & & Ref. & \\
\hline Geographic setting & & & & & & \\
\hline Rural & 1.03 & & $0.95,1.12$ & 1.00 & & $0.94,1.07$ \\
\hline Urban & & Ref. & & & Ref. & \\
\hline Year & & & & & & \\
\hline 2011 & 1.03 & & $0.96,1.11$ & 1.02 & & $0.96,1.08$ \\
\hline 2009 & & Ref. & & & Ref. & \\
\hline
\end{tabular}

FPL, federal poverty level; SNAP, Supplemental Nutrition Assistance Program; Ref., reference category. ${ }^{\star} P<0.05,{ }^{\star \star} P<0.005,{ }^{* \star *} P<0.0001$.

persisted post service ${ }^{(21)}$, and such emergent themes could further explain our results. For example, the authors reported that eating anything available was common during times of food insecurity during military service, as well as eating fast, binge eating and hoarding; all demonstrating a trend towards poor eating behaviour. In addition, veterans reported a preference for specific food items, such as burgers and fries, considered to be status foods due to putatively low access during deployment, and such diets high in fat and carbohydrates during military service persisted post service ${ }^{(21)}$. As such, the negative dietary behaviours noted among food-insecure veterans in our study are comparable to Smith et al.'s qualitative analyses, although our study adds quantitative data to the literature on specific dietary practices of consumption of fast foods, soda, fruits and vegetables and the relationship to food insecurity among such a vulnerable population.

Cumulatively, the literature and our results on the association between food insecurity and negative dietary practices among veterans highlight the imperative need for health promotion measures focused on a healthy diet in 
this population, especially those with limited access to healthy food options. Empirical evidence has demonstrated the effectiveness of price reduction of healthy foods ${ }^{(22)}$, faith-placed interventions and point-of-purchase incentives $^{(23)}$, and educational ${ }^{(24)}$ and voucher options ${ }^{(25)}$ to increase purchase and consumption of such items. For example, a faith-placed intervention incorporating motivational interviewing techniques was shown to increase intakes of fruits and vegetables among African Americans $^{(26)}$, while peer education worksite interventions have been shown to be effective in increasing healthy dietary behaviours among low-income adults ${ }^{(27)}$. Likewise, among women participating in government assistance programmes, vouchers for farmers' markets have been shown to significantly increase and sustain intakes of fruits and vegetables ${ }^{(28)}$. Similar community-based interventions incorporating motivational interviews at veteran centres, dietary counselling lines, vouchers and/or coupons for veterans on healthy food items, and faith-placed initiatives promoting access to healthy food items and choices, may help mitigate the burden of poor diet among food-insecure veterans.

Several additional factors associated with poor dietary behaviour among veterans, as found in our study, warrant further discussion and highlight target groups for aforementioned health promotion measures. For instance, SNAP participation was associated with lower fruit intake, consistent with previous literature that noted SNAP participants were less likely to consume fruits ${ }^{(29)}$. Such an association may be due to the higher cost of fruits and the financial burden of purchasing such items that participation in SNAP alone cannot alleviate. In an evaluation of the cost of fruits and vegetables, a report by the US Department of Agriculture demonstrated that the average retail price per pound $(\sim 450 \mathrm{~g})$ of fresh fruits ranged from $\$ \mathrm{US}$ $0 \cdot 26$ (watermelon) to \$US 7.29 (raspberries), while the average retail price per pound $(\sim 450 \mathrm{~g})$ of vegetables ranged from \$US 0.48 (potatoes) to \$US 4.02 (sliced mushrooms $)^{(30)}$. Since SNAP participants are likely to be low income and given the comparably higher price of fresh fruits, the association between SNAP participation and lower fruit intake could be attributed to such price differences, although further analysis of the association between price differences and food purchases among SNAP participants is needed.

Studies have found that post-service veterans are at risk of increased weight gain. In our study, we noted approximately $71 \%$ of veterans were overweight or obese, a prevalence comparable to or higher than that in other studies. While weight standards are required for the US military, much of the literature notes that post-discharge weight gain, and thus obesity prevalence among veterans, is comparable to or higher than that of their nonveteran counterparts $^{(1,4,31-34)}$. For example, in a study of approximately 1.8 million veterans Das and colleagues found approximately 37 and 33\% of women and men veterans to be obese, respectively ${ }^{(3)}$, while another study noted overweight status to be significantly higher among veterans than non-veterans ${ }^{(4)}$. Similarly, a higher prevalence of obesity has been documented among veterans utilizing Veterans Affairs health care, as compared with non-veterans ${ }^{(33)}$. The higher prevalence of overweight/ obese status in our study population could be attributable to a majority of the population being 45 years or older, with a higher proportion aged 65 years or more.

On the other hand, the reverse relationship between increasing age and poor dietary practices demonstrates that while older veterans were more likely to be overweight or obese, the younger groups in our study were the higher at-risk population for negative outcomes and thus susceptible to prolonged burden of chronic diseases including obesity. As such, significant efforts in health promotion should be targeted towards younger veterans to alleviate the abovementioned need for status foods and learned negative behaviours during service time, as highlighted by Smith et al. ${ }^{(21)}$.

While the relationship of low education and unemployment with poor dietary practices is not surprising and is consistent with previous established literature ${ }^{(35,36)}$, the association among veterans does highlight the need for ensuring adequate diet among such at-risk populations. Similarly, studies in the general population have documented poorer diet among males ${ }^{(36)}$, potentially due to stronger beliefs and control of weight management among females ${ }^{(37)}$, as was observed in our study among veterans.

Given that urban areas are more densely populated and thus more likely to have increased access to fast foods, the association between geographic location and fast food intake is not surprising; although the results do highlight the need for improved policies to implement stronger zoning laws to limit such establishments ${ }^{(38)}$.

The relationship between unhealthy diet and African American ethnicity may be attributed to the higher density of fast food places and lower access to healthy sources of foods in predominantly Black neighbourhoods ${ }^{(39,40)}$. Moreover, the lower intake of vegetables among Asian Americans could be attributable to the lack of Asian language-specific assessments of vegetables, such as okra or drumstick ${ }^{(41)}$. Moreover, studies among the general population have shown lower fruit and vegetable intakes among Asian Americans as compared with non-Hispanic Whites $^{(42)}$. As such, health promotion measures targeted at ethnic minority veterans are critical, similar to such measures among the general population. Likewise, given that veterans reporting health-risk behaviours of being a current smoker and binge drinking had poorer dietary practices, public health initiatives should aim to further promote positive health behaviours to counteract the already negative health effects of cigarette and alcohol use $^{(43-45)}$.

Two specific results in our study further warrant additional studies to comprehensively evaluate the underlying 
reasons for the association of obesity and perceived general health with soda intake. Our result on the inverse relationship between health status and soda intake could be attributable to continued public health efforts targeted at the negative health effects of soda; although lack of such an association with fast foods warrants further exploration in future studies. Similar to previous literature demonstrating the relationship between diet and self-perceived health ${ }^{(46)}$, our study also demonstrated that those with low self-perceptions of health were more likely to report higher soda intake, although no other dietary outcome yielded significance. While such results could be due to limitations of our population or other underlying factors not assessed in these cross-sectional data, further longitudinal studies are needed to comprehensively understand the association between self-perception and diet.

Additionally, the cross-sectional data of our study limit our ability to draw causal or temporal relationships between dietary outcomes and food insecurity. Moreover, the self-reported data of the CHIS are susceptible to bias and the lack of assessment of hunger in our study presents a limitation that could be addressed in future studies. Notwithstanding such limitations, the results of our study have significant implications to help mitigate the burden of obesity and associated negative health behaviours among veterans. Given the relationship between food insecurity and low fruit/vegetable intake and high fast food/soda intake, even after accounting for SNAP participation, public health efforts are of imperative need. As discussed earlier, such best practices of providing vouchers, coupons and targeted health education initiatives that promote healthy dietary behaviour among low-food-secure veterans, with follow-up counselling, are urgently needed.

\section{Acknowledgements}

Financial support: This research received no specific grant from any funding agency in the public, commercial or not-for-profit sectors. Conflict of interest: None. Authorship: M.B.B. and B.J.B. were co-principal investigators of the study. M.B.B. developed the conceptual framework for the study and conducted preliminary analysis. B.J.B. conducted the data analysis. M.M.B., C.M.H. and B.J.B. contributed to data interpretation and final approval for the manuscript. Ethics of buman subject participation: Only de-identified public-use secondary data were utilized in this study.

\section{References}

1. Koepsell TD, Littman AJ \& Forsberg CW (2012) Obesity, overweight, and their life course trajectories in veterans and non-veterans. Obesity (Silver Spring) 20, 434-439.

2. Kress AM, Hartzel MC \& Peterson MR (2005) Burden of disease associated with overweight and obesity among US military retirees and their dependents, aged 38-64, 2003. Prev Med 41, 63-69.

3. Das SR, Kinsinger LS, Yancy WS Jr et al. (2005) Obesity prevalence among veterans at Veterans Affairs medical facilities. Am J Prev Med 28, 291-294.

4. Koepsell TD, Forsberg CW \& Littman AJ (2009) Obesity, overweight, and weight control practices in US veterans. Prev Med 48, 267-271.

5. Kopelman PG (2000) Obesity as a medical problem. Nature 404, 635-643.

6. Nelson KM, McFarland L \& Reiber G (2007) Factors influencing disease self-management among veterans with diabetes and poor glycemic control. J Gen Intern Med 22, 442-447.

7. Wang A, Kinsinger LS, Kahwati LC et al. (2005) Obesity and weight control practices in 2000 among veterans using VA facilities. Obes Res 13, 1404-1411.

8. US Department of Agriculture, Economic Research Service (2015) Definitions of Food Security. http://www.ers.usda. gov/topics/food-nutrition-assistance/food-security-in-theus/definitions-of-food-security.aspx (accessed June 2015).

9. Huet C, Rosol R \& Egeland GM (2012) The prevalence of food insecurity is high and the diet quality poor in Inuit communities. J Nutr 142, 541-547.

10. Tarasuk VS \& Beaton GH (1999) Women's dietary intakes in the context of household food insecurity. J Nutr 129, 672-679.

11. Mello JA, Gans KM, Risica PM et al. (2010) How is food insecurity associated with dietary behaviors? An analysis with low-income, ethnically diverse participants in a nutrition intervention study. J Am Diet Assoc 110, 1906-1911.

12. Wang EA, McGinnis KA, Goulet J et al. (2015) Food insecurity and health: data from the Veterans Aging Cohort Study. Public Health Rep 130, 261-268.

13. Widome R, Jensen A, Bangerter A et al. (2015) Food insecurity among veterans of the US wars in Iraq and Afghanistan. Public Health Nutr 18, 844-849.

14. California Health Interview Survey (2013) About CHIS. http://healthpolicy.ucla.edu/chis/about/Pages/about.aspx (accessed June 2015).

15. Centers for Disease Control and Prevention (2012) Defining Adult Overweight and Obesity. http://www.cdc.gov/ obesity/adult/defining.html (accessed July 2015).

16. Kendall A, Olson CM \& Frongillo EA (1996) Relationship of hunger and food insecurity to food availability and consumption. I Am Diet Assoc 96, 1019-1024.

17. Robaina KA \& Martin KS (2013) Food insecurity, poor diet quality, and obesity among food pantry participants in Hartford, CT. J Nutr Educ Behav 45, 159-164.

18. Drewnowski A \& Darmon N (2005) Food choices and diet costs: an economic analysis. J Nutr 135, 900-904.

19. Drewnowski A \& Darmon N (2005) The economics of obesity: dietary energy density and energy cost. Am J Clin Nutr 82, 1 Suppl., 265S-273S.

20. Jetter KM \& Cassady DL (2006) The availability and cost of healthier food alternatives. Am J Prev Med 30, 38-44.

21. Smith C, Klosterbuer A \& Levine AS (2009) Military experience strongly influences post-service eating behavior and BMI status in American veterans. Appetite 52, 280-289.

22. French SA (2003) Pricing effects on food choices. J Nutr $\mathbf{1 3 3}$, issue 3, 841S-843S.

23. Glanz K \& Yaroch AL (2004) Strategies for increasing fruit and vegetable intake in grocery stores and communities: policy, pricing, and environmental change. Prev Med 39, Suppl. 2, S75-S80.

24. Marcus AC, Heimendinger J, Wolfe P et al. (2001) A randomized trial of a brief intervention to increase fruit and vegetable intake: a replication study among callers to the CIS. Prev Med 33, 204-216. 
25. Anderson JV, Bybee DI, Brown RM et al. (2001) 5 a day fruit and vegetable intervention improves consumption in a low income population. J Am Diet Assoc 101, 195-202.

26. Resnicow K, Jackson A, Wang T et al. (2001) A motivational interviewing intervention to increase fruit and vegetable intake through Black churches: results of the Eat for Life Trial. Am J Public Health 91, 1686-1693.

27. Buller DB, Morrill C, Taren D et al. (1999) Randomized trial testing the effect of peer education at increasing fruit and vegetable intake. J Natl Cancer Inst 91, 1491-1500.

28. Herman DR, Harrison GG, Afifi AA et al. (2008) Effect of a targeted subsidy on intake of fruits and vegetables among low-income women in the Special Supplemental Nutrition Program for Women, Infants, and Children. Am J Public Health 98, 98-105.

29. Leung CW, Ding EL, Catalano PJ et al. (2012) Dietary intake and dietary quality of low-income adults in the Supplemental Nutrition Assistance Program. Am J Clin Nutr 96, 977-988.

30. Stewart H, Hyman J, Buzby J et al. (2011) How Much Do Fruits and Vegetables Cost? Economic Information Bulletin no. EIB-71. http://www.ers.usda.gov/media/133287/eib71. pdf (accessed June 2015).

31. Almond N, Kahwati L, Kinsinger L et al. (2008) Prevalence of overweight and obesity among US military veterans. Mil Med 173, 544-549.

32. Littman AJ, Jacobson IG, Boyko EJ et al.; Millennium Cohort Study Team (2013) Weight change following US military service. Int J Obes (Lond) 37, 244-253.

33. Nelson KM (2006) The burden of obesity among a national probability sample of veterans. J Gen Intern Med 21, 915-959.

34. Teachman J \& Tedrow L (2013) Veteran status and body weight: a longitudinal fixed-effects approach. Popul Res Policy Rev 32, 199-220.

35. Ervin RB (2008) Healthy Eating Index scores among adults, 60 years of age and over, by sociodemographic and health characteristics: United States, 1999-2002. Adv Data issue 395, 1-16.
36. Hiza HAB, Casavale KO, Guenther PM et al. (2013) Diet quality of Americans differs by age, sex, race/ethnicity, income, and education level. I Acad Nutr Diet 113, 297-306.

37. Wardle J, Haase AM, Steptoe A et al. (2004) Gender differences in food choice: the contribution of health beliefs and dieting. Ann Behav Med 27, 107-116.

38. Centers for Disease Control and Prevention (2015) Zoning to Encourage Healthy Eating. http://www.cdc.gov/phlp/ winnable/zoning_obesity.html (accessed June 2015).

39. Powell LM, Chaloupka FJ \& Bao Y (2007) The availability of fast-food and full-service restaurants in the United States: associations with neighborhood characteristics. Am J Prev Med 33, 4 Suppl., S240-S245.

40. Franco M, Diez Roux AV, Glass TA et al. (2008) Neighborhood characteristics and availability of healthy foods in Baltimore. Am J Prev Med 35, 561-567.

41. Ansari NM, Houlihan L, Hussain B et al. (2005) Antioxidant activity of five vegetables traditionally consumed by SouthAsian migrants in Bradford, Yorkshire, UK. Phytother Res 19, 907-911.

42. Maxwell AE, Crespi CM, Alano RE et al. (2012) Health risk behaviors among five Asian American subgroups in California: identifying intervention priorities. $J$ Immigr Minor Health 14, 890-894.

43. Thun MJ, Carter BD, Feskanich D et al. (2013) 50-year trends in smoking-related mortality in the United States. $N$ Engl J Med 368, 351-364.

44. Conroy RM, Pyörälä K, Fitzgerald AP et al. (2003) Estimation of ten-year risk of fatal cardiovascular disease in Europe: the SCORE project. Eur Heart J 24, 987-1003.

45. Mukamal KJ, Maclure M, Muller JE et al. (2005) Binge drinking and mortality after acute myocardial infarction. Circulation 112, 3839-3845.

46. Lu N, Samuels ME \& Huang K-C (2002) Dietary behavior in relation to socioeconomic characteristics and selfperceived health status. $J$ Health Care Poor Underserved 13, 241-257. 